\title{
The importance of paleoecology in the conservation and restoration of cultural landscapes
}

\author{
Anneli Ekblom¹ and Lindsey Gillson²
}

\section{Cultural landscapes are enormously biodiverse. Presently, customary management of cultural landscapes is diminishing, resulting in loss of biodiversity and landscape heterogeneity. Here, we stress the role of paleoecology and other forms of paleoscience in restoring productive and biodiverse landscapes.}

Extinction rates today rival the five major previous extinction events in Earth's history. The biggest loss of biodiversity is due to land-use change, for example the conversion of forests, grasslands and other habitats through cultivation and urbanization, as well as the degradation and fragmentation of habitats (MA 2005). Stressed and fragmented ecosystems and populations are also less resilient to changing climate and other impacts such as pollution and invasive species. Restoration of ecosystem function, resilience and adaptive capacity is equally as important as maintaining species richness; therefore, different land-management options need to be considered. Intensive agricultural systems provide little wildlife habitat, whereas many land areas under traditional management (e.g. small-scale, low-intensive agricultural practices, referred to hereafter as customary) are significant havens for biodiversity (Fischer et al. 2012; Gillson 2015). Many cultural landscapes are biodiverse and are considered as important conservation targets (Agnoletti 2014). For example, cultural landscapes are now part of the International Union for Conservation of Nature protected areas classification. However, many customary management techniques have been eroded due to socioeconomic pressures, with a subsequent loss of biodiversity and landscape heterogeneity. There is therefore a need to review customary management practices and the landscapes they produce, and to revive and reinforce the adaptive management techniques that are embodied in traditional land-use systems.

\section{A role for paleoecology in landscape management}

There is a role for paleoecology and other forms of long-term science in restoring productive, biodiverse landscapes. In many areas of Europe, rural land abandonment has led to the degradation of semi-natural

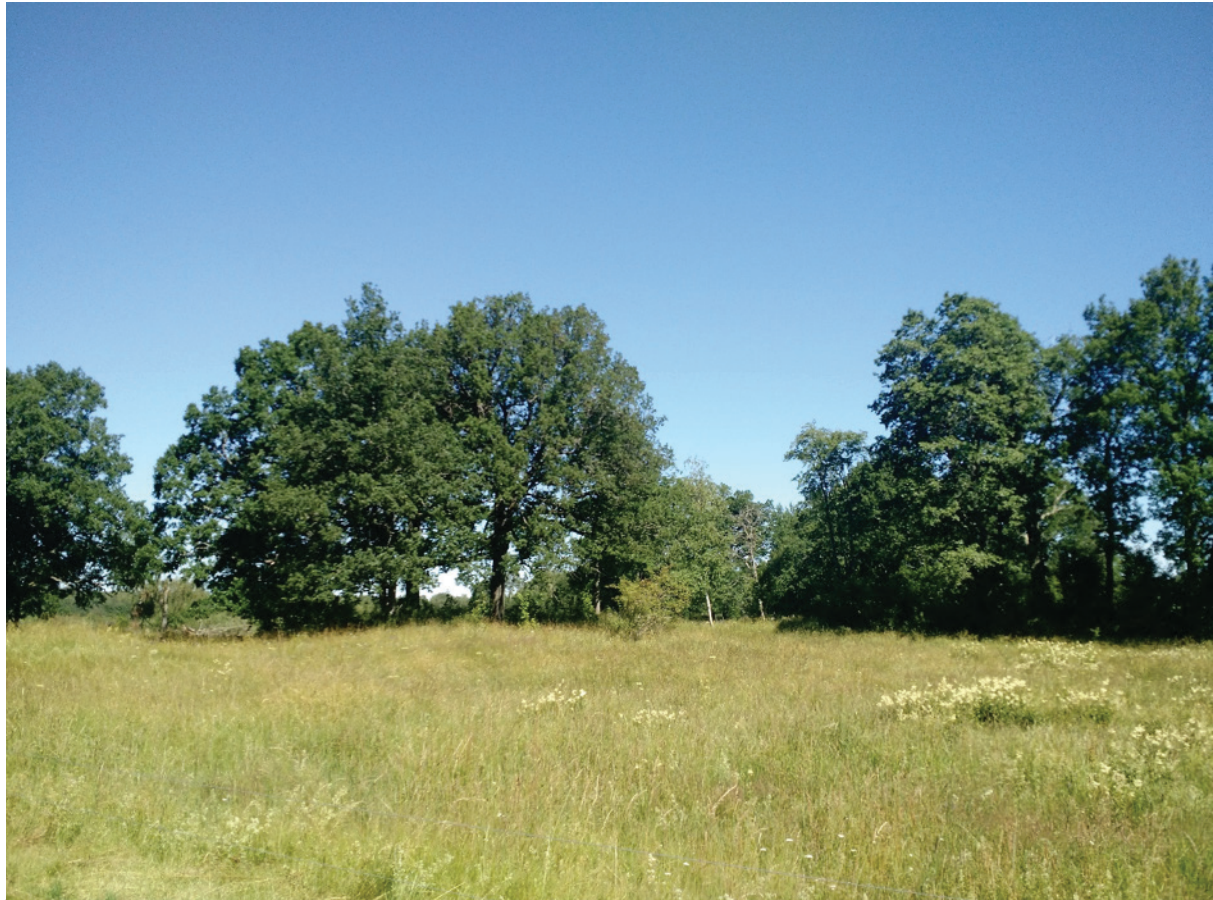

Figure 1: Oakmeadow, central Sweden, is regularly grazed by cows to maintain the open meadow vegetation. Photo: Siri Pettersson. woodlands, meadows and heathlands due to the discontinuation of customary practices (Weissteiner et al. 2011). Many species of high conservation value are specifically associated with these cultural landscapes and require a continued and active management. In Europe, 55 of the 231 listed habitat types of European interest depend on, or benefit from, continued customary practices (EEA 2011).

Paleoecological and historical studies have consistently shown a decrease in biodiversity associated with the loss of customary land-management practices, and higher biodiversity associated with low-intensity land uses, which generate mosaics of wooded and grassy habitats. For example, Swedish semi-natural woodpastures and forest mead ows are important examples of relict cultural landscapes in Europe. Paleoecological research has shown a decrease in the diversity of forest taxa within the last centuries as the result of the reduction in grazing and mowing practices and accompanying canopy closure, with detrimental effects on the mixed deciduous forests trees such as lime (linden) and beech. Paleoecological knowledge has been important in the management of these landscapes (Bradshaw and Lindbladh 2005). Similarly, remnants - a function of old grazing practices, such as oak meadows (oak savannas) - are now threatened through the lack of grazing and management (Fig. 1). Dahlström et al. (2008) show that the highest species richness in plants in central Sweden is found in what today is semi-natural grassland subjected to a long continuity of grazing. It is estimated that since $1870,99.7 \%$ of the semi-natural hay meadows have been lost, the few remaining semi-natural hay meadows are now managed mainly for conservation purposes. In this case, long-term data may provide knowledge on management practices that have now been lost.

In Tuscany, Italy, there has been a $45 \%$ decrease of landscape mosaics between 18322004, due to the combination of EU regulations in the agricultural and forestry sectors (Agnoletti 2006; Fig. 2). Historical analyses show that meadows and chestnut orchards 


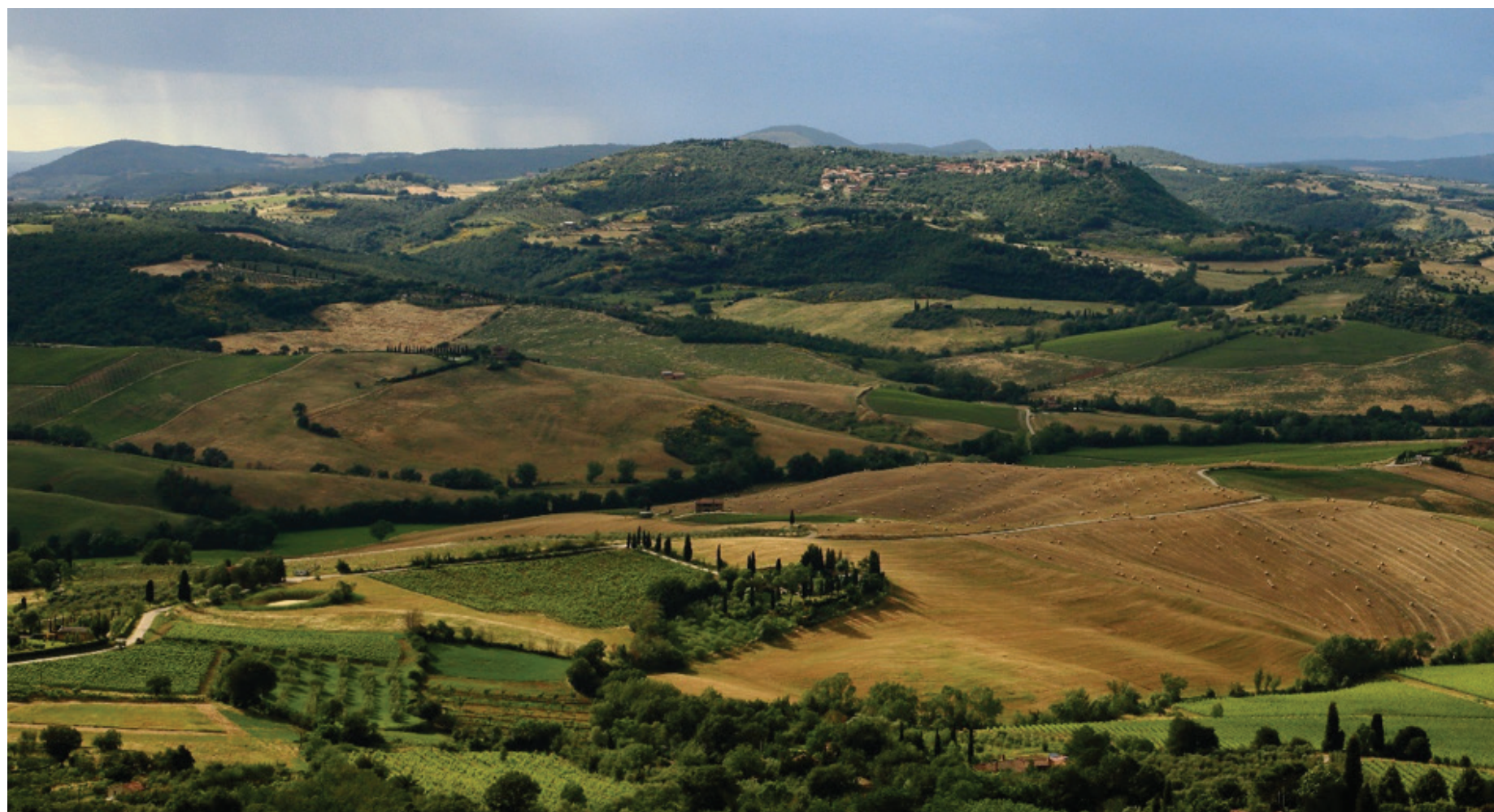

Figure 2: Tuscany landscape. Photo: Martin Falbisoner, Wikimedia Commons.

are being replaced by forest expansion, with an overall loss in landscape heterogeneity, biodiversity and ecosystem services. Pastoral customary practices often combine grazing with fire management to maintain wood pastures, but since the 18th century many state authorities have actively used fire both in agriculture and forestry. Shakesby et al. (2011) showed an increase in wildfire and erosion following rural land abandonment in the Mediterranean region, associated with increased shrub cover and afforestation with flammable species. Paleoecological studies in the Pyrenees have shown that these pastoral landscapes have been systematically managed by fire over millennia (Mazier et al. 2006) and similar results have been shown for the Iberian Peninsula (Gil-Romera et al. 2010). In Scandinavia, the ecological role of fire in both semi-natural and old growth forests is now being realized (Bradshaw and Hannon 2006). In the Finnish boreal forests, dominated by the conifers Scots pine (Pinus sylvestris) and Norway spruce (Picea abies), local slash-and-burn practices were common until the early 20 th century. The mixed forests and grazing lands within the boreal forests are now experiencing a degradation and reduction in species diversity as slashand-burn practices have been discontinued (Myllyntaus et al. 2002). In other parts of Scandinavia, the historical importance of fires in the boreal forests is shown by the presence of fire-adapted species (Bradshaw and Hannon 2006). In all cases listed above, paleoecological knowledge is essential in managing and restoring landscapes, and for the protection and management of rare species through sound management practices (Gillson 2015).

\section{The importance of co-learning}

With only $12 \%$ of land in protected areas globally, conservation strategies are needed that integrate food production and biodiversity conservation. Intensive agricultural systems provide little wildlife habitat, whereas many land areas under customary management are compatible with biodiversity conservation and provide a wider range of ecosystem services. Cultural landscapes are now an important conservation target, but many customary systems have been eroded due to socio-economic pressures.

Alongside historical studies and stakeholder participation, paleoecological data can help to identify periods of time in which biodiversity and food production co-existed, enabling realistic future scenarios to be envisioned (Gillson 2015). Landscape management needs targets for both the extent and configuration of habitats needed to maintain species, plus political arenas where stakeholders can resolve (the inevitable) conflicts arising from different land-use practices and goals (Angelstam 2006). Rural areas where customary practices are in use today are often either marginal or remote with poorly developed infrastructure, and areas that typically lie very far from the centers of political power where decisions are made. As most biodiversity protection will have to be provided by local initiative and through local practices, we need to better understand and encourage local interest in building and maintaining cultural landscapes. Most importantly, local practitioners, farmers and smallholders or herders must have a place at the negotiating table. Co-learning and co-production of landscape management plans can help to foster ecological and social resilience, as well as nurturing social cohesion and a sense of place, resulting in more effective landscape stewardship.

\section{AFFILIATIONS}

'Department of Archaeology and Ancient History, Uppsala University, and Centre for Environment and
Development Studies (Cemus, Uppsala University and Swedish University of Agricultural Sciences), Sweden ${ }^{2}$ Department of Biological Sciences, University of Cape Town, South Africa

\section{CONTACT}

Anneli Ekblom: anneli.ekblom@arkeologi.uu.se

\section{REFERENCES}

Agnoletti M (2006) In: Agnoletti M (Ed) The Conservation of Cultural Landscapes. CABI Publishing, 3-29

Agnoletti M (2014) Landscape and Urban Planning 126 : 66-73

Angelstam P (2006) In: Agnoletti M. (Ed) The

Conservation of Cultural Landscapes. CABI Publishing, 125-143

Bradshaw RHW, Hannon GE (2006) In: Agnoletti M (Ed)

The Conservation of Cultural Landscapes. CAB Publishing 94-107

Bradshaw RHW, Lindbladh M (2005) Ecology 86 : 1679-1685

Dahlström A et al. (2008) Env Hist 14: 385-403 EEA (2011) http://www.eea.europa.eu/themes/agriculture Fischer J et al. (2012) Cons Lett 5: 167-175

Gillson L (2015) Biodiversity Conservation and Environmental Change: Using Paleoecology to Manage Dynamic Landscapes in the Anthropocene, Oxford University Press, 272pp

Gil-Romera G et al. (2010) Quat Sci Rev 29: 1082-1092 MA (2005) Millennium Ecosystem Assessment. Ecosystems and Human Well-being: Synthesis, Island Press, 139pp

Mazier F et al. (2006) Holocene 16: 91-103

Myllyntaus T et al. (2002) Env Hist 7: 267-302

Shakesby R (2011) Earth Sci Rev 105: 71-100

Wiessteiner CJ et al. (2011) Glob Planet Change 79: 20-36 